\title{
A novel hot-melt extrusion formulation of albendazole for increasing dissolution properties
}

\section{Laura Martinez-Marcos ${ }^{1,2} *$, Dimitrios A. Lamprou ${ }^{1,2} *$, Roy T. McBurney ${ }^{1,2}$, Gavin W. Halbert ${ }^{1,2} * *$}

${ }^{1}$ EPSRC Centre for Innovative Manufacturing in Continuous Manufacturing and Crystallisation (CMAC), University of Strathclyde, Technology and Innovation Centre, 99 George Street, G1 1RD Glasgow, United Kingdom

${ }^{2}$ Strathclyde Institute of Pharmacy and Biomedical Sciences, University of Strathclyde, 161 Cathedral Street, G4 0RE Glasgow, United Kingdom

* Corresponding authors. E-mail address: laura.martinez-marcos@strath.ac.uk, dimitrios.lamprou@strath.ac.uk

Tel.: +441415484968

** Funded by Cancer Research UK

\section{ABSTRACT}

The main aim of the research focused on the production of hot-melt extrusion (HME) formulations with increased dissolution properties of albendazole (ABZ). Therefore, HME was applied as a continuous manufacturing technique to produce amorphous solid dispersions of the poorly water soluble drug ABZ combined with the polymer matrix polyvinylpyrrolidone PVP K12. HME formulations of ABZ - PVP K12 comprised a drug content of $1 \%, 5 \%$ and $10 \% \mathrm{w} / \mathrm{w}$. The main analytical characterisation techniques used were Scanning Electron Microscopy (SEM), Micro-computed Tomography ( $\mu$-CT), X-Ray Powder Diffraction (XRPD), Differential Scanning Calorimetry (DSC) and dissolution profile 
studies. The application of SEM, XRPD and DSC evidenced drug physical transformation from crystalline to amorphous state and therefore, the achievement of an amorphous solid dispersion. The introduction of a novel technique, $\mu-\mathrm{CT}$, to characterise the internal structure of these materials revealed key information regarding materials distribution and void content. Dissolution profile studies evidenced a high increase in drug release profile compared to pure ABZ. These promising results can lead to a great enhancement of the oral bioavailability of ABZ dosage forms. Therefore, HME is a potential continuous manufacturing technique to overcome $\mathrm{ABZ}$ poor solubility properties and lead to a significant increase in the therapeutic effect.

Keywords: Hot-melt extrusion; Amorphous solid dispersions; Albendazole; Continuous manufacturing; $\mu$-CT.

\section{Introduction}

A major focus of current pharmaceutical industry research is directed at the need to manufacture and deliver better quality medicines in a cost efficient manner (Madan and Madan, 2012). However, the physicochemical properties of Active Pharmaceutical Ingredients (APIs) are not always ideal and properties such as poor aqueous solubility, which influences dissolution and oral bioavailability, can be detrimental during pharmaceutical development (Munos, 2009; Kawakami, 2012). APIs that exhibit low solubility properties but high permeability through biological membranes are considered Class II compounds within the Biopharmaceutics Classification System (BCS) (Lindenberg et al., 2004) and in order to overcome poor solubility properties several formulation techniques can be considered. Some of the most common approaches are the introduction of chemical transformations such as the production of salt or co-crystal forms and other process modifications for example drug 
micronisation or the production of amorphous solid dispersions (Stegemann et al., 2007; Kawabata et al., 2011; Jones et al., 2014).

It has been recognised that a change in the API's molecular physical state from a crystalline ordered structure to an amorphous state dramatically enhances its solubility and dissolution properties (Zhang et al., 2004). This physical transformation of the drug can be achieved by Hot-Melt Extrusion (HME) in order to deliver an amorphous solid dispersion with increased dissolution properties, which is controlled by the polymeric carrier excipient combination employed.

HME is a widely known manufacturing process that has been used in the plastic (Michaeli et al., 1993) and food industries (Cheng and Friis, 2010) and more recently, in the pharmaceutical industry (Crowley et al., 2007). In HME, a hydrophilic polymeric carrier and a poor water soluble drug are homogeneously mixed to form a molecular solid dispersion (Repka et al., 2007). HME can be achieved using a single or twin-screw extruder, both types have been widely studied and the advantages and disadvantages regarding the material mixing achieved reviewed (Van zuilichem et al., 1999). Selection of the components must be carefully performed taking into account the melt temperature $(\mathrm{Tm})$ of both the polymer and the API as well as the glass transition temperature $(\mathrm{Tg})$ of the polymer. These parameters play a key role in obtaining an amorphous solid dispersion as well as being key determinants of product stability (Newman et al., 2012). Initial assessment of the solubility properties can be performed by evaluating drug-polymer miscibility properties or also by using a mathematical approach such as the Hoy and Hoftzyer/Van Krevelen method (Forster et al., 2001). After production, characterisation techniques such as X-Ray Powder Diffraction (XRPD) and thermal analysis by Differential Scanning Calorimetry (DSC) constitute important techniques for the assessment of drug solid state (Maniruzzaman et al., 2013). Previous HME applications have focused on the development of new drug delivery systems 
such as sustained released or taste-masking formulations (Maniruzzaman et al., 2012; Gue et al., 2013; Schilling and McGinity, 2010; Verhoeven et al., 2009b). By applying modelling techniques such as Computational Fluid Dynamics (CFD), Eitzlmayr et al., (2014), demonstrated that HME processes can be fully designed and noted the importance of selecting adequate screw elements configuration as this has an impact on the screws filling degree and therefore the heat transfer mechanisms within the extruder. Moreover, processing parameters such as melt temperature can be calculated taking into account the polymer's and API's viscosity values. Finally Quality by Design (QbD) has emerged as a potent tool to investigate the working space limits of HME processes based on the desired product specifications (Thiry et al., 2015; Maughan and Rhamzan, 2012).

The main aim of this research comprised the development and characterisation of novel albendazole (ABZ) formulations manufactured by continuous HME processing to improve ABZ dissolution properties and determine the influence of different drug contents in relation to material properties such as drug content uniformity, materials homogeneity and internal porosity by the application of a novel technique such as micro computed tomography $(\mu-\mathrm{CT})$. ABZ is an anthelmintic drug used in the treatment of hydatid disease, among other parasitic worm infestations. Reported physicochemical properties of ABZ such as a low aqueous solubility of $0.0228 \mathrm{mg} / \mathrm{mL}$ and a melting temperature $(\mathrm{Tm})$ of $208^{\circ} \mathrm{C}$ were crucial to determine the suitability of this drug molecule for HME processing. APIs with a high melting point are preferred to avoid any degradation product as it has been previously observed using temperature sensitive drugs. It is also widely known that the low solubility and dissolution rate of $\mathrm{ABZ}$ lead to erratic absorption (below 5\%) from the gastrointestinal tract mainly observed through pharmacokinetic studies (Marriner et al., 1986; Jung et al., 1998). Moreover, Newman et al., (2012), classified ABZ as one of the BCS II compounds where a 
International Journal of Pharmaceutics

solid phase transformation using a hydrophilic polymer such as PVP could become a suitable approach towards the enhancement of its oral bioavailability.

Previous work comprising solid dispersions of ABZ and PVP K12 manufactured by solvent evaporation method was carried out by Torrado et al., (1996) in order to improve ABZ dissolution rate. In our study we were able to successfully produce stable amorphous solid dispersions of $\mathrm{ABZ}$ by $\mathrm{HME}$ process with increased dissolution properties and provide novel characterisation studies by the application of $\mu-\mathrm{CT}$.

\section{Materials and methods}

\subsection{Materials}

Albendazole (ABZ, $\geq 98 \%$ ) was purchased from Sigma-Aldrich Company Ltd. (Gillingham, Dorset, United Kingdom). Pharmaceutical grade polyvinylpyrrolidone K12 (PVP K12 PF), was kindly donated by BASF (Cheshire, United Kingdom). Other reagents such as methanol (HPLC grade, $\geq 99.5 \%$ ), potassium chloride AR grade, sodium dihydrogen phosphate ( $>99.0$ $\%$ ) and glacial acetic acid (ACS reagent, $\geq 99.7 \%$ ) were obtained from Sigma-Aldrich.

\subsection{Miscibility studies}

Miscibility properties of ABZ and PVP K12 were theoretically assessed using the Hansen solubility parameter calculations and confirmed by hot-stage microscopy (HSM) using a Reichert-Jung polyvar optical microscope fitted with a hot-stage. Raw materials, physical mixtures $(\mathrm{PM})$ at 1/99, 5/95 and 10/90 \% w/w and extruded materials were studied using a heating rate of $10{ }^{\circ} \mathrm{C} / \mathrm{min}$.

\subsection{Continuous manufacturing by Hot-Melt Extrusion (HME)}

Formulations of ABZ and PVP K12 comprising 1/99, 5/95 and 10/90 (\% w/w) (F1, F2 and F3, total sample weight of $50 \mathrm{~g}$ ) were prepared (Jones et al., 2014; Kelly et al., 2015). Previous sieving of PVP K12 through a mesh of $250 \mu \mathrm{m}$ was carried out for particle size 
homogenisation purposes. Physical mixtures of ABZ - PVP K12 were manually blended for 2-5 minutes prior extrusion. All formulations were processed by HME using a Thermo Scientific ${ }^{\circledR}$ Process 11 co-rotating twin-screw extruder (40L/D) (Karlsruhe, Germany) with the following standard screw configuration: (FS 11/40) $\times 7+\left(\operatorname{KE~} 10 / 90^{\circ}\right) \times 8+\left(\operatorname{KE~} 10 / 60^{\circ}\right)$ $\mathrm{x} 4(\mathrm{~F})+(\mathrm{FS} 11 / 40) \times 8+\left(\mathrm{KE} 10 / 60^{\circ}\right) \times 6(\mathrm{~F})+(\mathrm{FS} \mathrm{11/40)} \times 7+(\mathrm{KE} \mathrm{10/90}) \times 4+(\mathrm{KE}$ $\left.10 / 60^{\circ}\right) \times 3(\mathrm{~F})+\left(\mathrm{KE} 10 / 30^{\circ}\right) \times 5(\mathrm{~F})+(\mathrm{FS} \mathrm{11/40)} \times 9$; (FS 11/40: feed screw with a pitch of $11 \mathrm{~mm}$ and length of $40 \mathrm{~mm}$; KE $10 / 90^{\circ}$ : kneading element with thickness of $10 \mathrm{~mm}$ and $90^{\circ}$ offset angle; $\mathrm{KE} 10 / 60^{\circ}$ : kneading element with thickness of $10 \mathrm{~mm}$ and $60^{\circ}$ offset angle; $\mathrm{KE}$ $10 / 30^{\circ}$ : kneading element with thickness of $10 \mathrm{~mm}$ and $30^{\circ}$ offset angle; F: forward). The 11 $\mathrm{mm}$ screw diameter extruder was fitted with a single orifice die of $2.0 \mathrm{~mm}$ diameter and processing parameters are presented in Table 1. Cooling of the strands was performed at room temperature and then stored in a sealed glass container under temperature controlled conditions of $25^{\circ} \mathrm{C}$ and $50{ }^{\circ} \mathrm{C}$. Initial studies of all extruded materials were performed at zero time and stability studies performed after 1, 3 and 6 months storage under conditions indicated in the text.

\subsection{Scanning Electron Microscopy (SEM)}

HME formulations containing ABZ - PVP K12 were analysed by SEM for the presence of crystalline ABZ. Gold-coated samples of the extruded materials were mounted on the sample holder using silver paint and uncoated samples of pure ABZ and physical mixtures $\mathrm{ABZ}-$ PVP K12 were mounted using double-sided conductive tape. Measurements were performed using a Hitachi SU 6600 high-resolution analytical FE-SEM (New York, United States) at 5.00 and $20.00 \mathrm{kV}$ and a Zeiss IS50 (Oberkochen, Germany) at $20.00 \mathrm{kV}$.

\subsection{Computed Tomography $(\mu-C T)$}

Cross-sections of the extruded materials were analysed by CT x-rays scanning to assess the internal void content (porosity) at a microstructural level, as well as sample uniformity by the 
characterisation of the average molecular densities. A Bruker high resolution X-ray MicroCT SkyScan 1272 (Kontich, Belgium) with an X-ray source voltage of $50 \mathrm{kV}$ was used. The system was equipped with an aluminium $0.25 \mathrm{~mm}$ filter and $11 \mathrm{Mp}$ CCD detector. Sample preparation required the introduction of a piece of extruded material inside a drinking straw to avoid any interference due to sample movement during measurement. Extruded material of ABZ - PVP K12 at 1/99 (\% w/w) was analysed using a rotation step of $0.6^{\circ}$ and extruded materials at $5 / 95$ and $10 / 90(\% \mathrm{w} / \mathrm{w})$ a rotation step of $0.10^{\circ}$ and exposure time of $300 \mathrm{~ms}$. The scanned images were reconstructed using the NRecon software (version 1.6.9.18, Bruker Micro-CT, Kontich, Belgium). To visualise and analyse the data, CTAn software (version 1.14.4.1, Bruker, Micro-CT, Kontich, Belgium) and CTVol software (version 2.2.3.0, Bruker Micro-CT, Kontich, Belgium) for surface rendering were used. A set of calculations within CTAn including image thresholding were applied to determine a region of interest (ROI) within the cross section of the extruded material and avoid any interference caused by the straw. Porosity calculations were performed considering the volume of internal closed pores which are completely surrounded by solid material.

All extruded materials were analysed by XRPD in order to determine the molecular transformation of the drug from crystalline to amorphous state. A Bruker AXS D8 advanced transmission diffractometer (Karlsruhe, Germany) with theta-theta geometry, primary monochromatic radiation $(\mathrm{Cu} K \alpha 1 \lambda=1.54056 \AA)$, a Braun 1D position sensitive detector (PSD) and an automated multi-position $x-y$ sample stage were used. Raw materials and physical mixtures drug-polymer were also characterised, and their XRPD patterns compared with the extruded materials. 
Thermal analysis of the extruded materials, physical mixtures drug-polymer and raw materials was performed using a Mettler Toledo DSC $822^{\mathrm{e}}$ (Greifensee, Switzerland) differential scanning calorimeter. A standard In/Zn calibration was performed and an inert gas such as $\mathrm{N}_{2}$ was used to purge throughout the equipment at $150 \mathrm{~mL} / \mathrm{min}$. Samples were ground using a mortar and pestle then introduced into $40 \mu \mathrm{l}$ sealed aluminium crucibles with a pierced lid. All samples were heated from 25 to $250{ }^{\circ} \mathrm{C}$, melting temperature $(\mathrm{Tm})$ of $\mathrm{ABZ}$ $\left(208-210{ }^{\circ} \mathrm{C}\right)$, at a heating rate of $10{ }^{\circ} \mathrm{C} / \mathrm{min}$, data was evaluated using the Star ${ }^{\circledR}$ Evaluation Software and the Tg events were characterised using the inflection method.

\subsection{Karl-Fischer studies for stability evaluation}

A Mettler Toledo DL-39 Karl-Fischer instrument (Schwerzenbach, Switzerland) was used to assess the water content of the extruded materials after 1, 3 and 6 months storage. Previous sample preparation required grinding of the sample using a mortar and a pestle followed by dissolution of $10 \mathrm{mg}$ of extruded material in $1 \mathrm{~mL}$ of methanol. Experiments were performed in chambers with controlled temperature and $\mathrm{RH}$.

\subsection{Dissolution profile studies}

Dissolution studies of the extruded materials and physical mixtures were carried out using a Sirius T3 measurement system (East Sussex, United Kingdom). Sample preparation required manual grinding using a mortar and a pestle to a fine powder. Particle size distributions of these materials were analysed (sample measurement time of $3 \mathrm{~s}$ ) using a Malvern Mastersizer 3000 (Worcestershire, United Kingdom) fitted with the Aero $S$ dry dispersion unit, a micro tray and air pressure adjusted to 1 bar. Mean values $\left(d_{10}, d_{50}, d_{90}\right)$ obtained for PM of ABZ PVP K12 at 1/99, 5/95 and 10/90 \% w/w were 21.11, 61.09, $110.38 \mu \mathrm{m}, 15.41,50.48,97.78$ $\mu \mathrm{m}$ and $10.55,46.11,90.46 \mu \mathrm{m}$, respectively. Moreover, mean values $\left(d_{10}, d_{50}, d_{90}\right)$ of extruded materials at 1/99, 5/95 and 10/90 \% w/w were 33.93, 197.46, $463.48 \mu \mathrm{m}, 18.01$, 123.54, $425.15 \mu \mathrm{m}$ and $8.65,88.90,459.85 \mu \mathrm{m}$, respectively. Later sample preparation 
included the formation of a $3 \mathrm{~mm}$ diameter single tablet by weighing between 7 to $12 \mathrm{mg}$ of grinded material that was later considered for dosage adjustment of each formulation. Tablets were pressed using a custom made die and a Specac manual hydraulic press (Kent, United Kingdom) with a compaction pressure of $80 \mathrm{kN}$. A Sirius T3 measurement system was then used to obtain material dissolution profiles between $\mathrm{pH}$ values of 2 to 7 . A stationary disk apparatus was used consisting of a tablet holder where die and tablet were inserted and analysed using $15 \mathrm{~mL}$ of acetate phosphate buffer dissolution media. The buffer media was used to simulate in-vitro gastrointestinal conditions by $\mathrm{pH}$ automatic adjustment from 2.0-3.7 (time 0-30min), 3.7-5.2 (time 30-60min), 5.2-7.1 (time 60-90min), and 7.1 (time 90-130min) and tablet surface facing the media to facilitate tablet erosion. Physical mixtures as well as extruded materials produced were analysed under non-sink conditions by a titration method. Datapoints were collected every 30 seconds by an spectroscopic UV dip-probe at a wavelength of $250 \mathrm{~nm}$ and transformed using pKa values $(4.08 ; 10.34)$ and Molar Extinction Coefficient (MEC) into dissolution profile curves representing drug release (\%) over time.

\section{Results and discussion}

\subsection{Miscibility studies}

The application of the Hoy and Hoftzyer/Van Krevelen method through the Hansen solubility parameter calculation evidenced that ABZ and PVP K12 are highly miscible, with a solubility parameter difference $(\Delta \delta)$ of $5.70 \mathrm{MPa}^{1 / 2}$. Individual solubility parameter values $(\delta)$ for $\mathrm{ABZ}$ and PVP K12 were previously calculated based on the contribution of dispersive forces $\left(\mathrm{E}_{\mathrm{d}}\right)$, polar interactions $\left(E_{p}\right)$ and hydrogen bonds $\left(E_{h}\right)$. Physical mixtures of ABZ and PVP K12 were also characterised by Hot-Stage Microscopy (HSM) to assess the miscibility properties of the two components and also their suitability for HME processing. Figure 1, a-d illustrates pure $\mathrm{ABZ}$ sample and images e-g the results of the physical mixture of ABZ - PVP K12 at 10/90 (\% w/w) under different temperature conditions. Solid ABZ appears as dark crystals 
using a 10x magnification lens, similar to the results observed by Moyano et al., (2014) using 100x magnification. In their study, commercial ABZ melting event is characterised at an onset temperature of $186{ }^{\circ} \mathrm{C}$ and complete melting is observed at $216^{\circ} \mathrm{C}$. Similar results are shown in Figure 1, images a to d where commercial ABZ particles are stable at temperatures between 45 to $180{ }^{\circ} \mathrm{C}$ but complete melting event is shown at $210{ }^{\circ} \mathrm{C}$. A physical mixture, ABZ - PVP K12 at 10/90 (\% w/w), shows a characteristic birefringence property that allows the differentiation between amorphous polymer and ABZ crystals (Fig. 1, e to g). Initial stages of polymer melting can be observed at a temperature of $145{ }^{\circ} \mathrm{C}$ (Fig. 1f) similar to DSC thermal analysis behaviour observed by Baird and Taylor (2012) and at $180{ }^{\circ} \mathrm{C}$, drug crystals dissolve within the polymer indicating the miscibility properties of the two materials (Fig. 1g). These results confirm the ability of ABZ and PVP K12 to form a miscible system when temperatures above the $\mathrm{Tg}$ of the polymer are applied $\left(\mathrm{Tg}\right.$ of PVP $\left.\mathrm{K} 12=90{ }^{\circ} \mathrm{C}\right)$ (Reintjes, 2011).

\subsection{Scanning Electron Microscopy (SEM)}

All formulations processed by HME were characterised by SEM microscopy in order to assess the physical state of the drug within the polymeric matrix, and extruded materials appear to be homogeneous when compared to the physical mixtures (Figure 2, b to d). It was also observed that as the amount of drug increased the porosity within the samples also increased which suggests that there is a correlation between the PVP K12 polymer and the proportion of drug in the system with the relaxation properties exhibited by the extruded materials (Sarode and Kumbharkhane, 2012). Moreover, polymer surface analysis of extruded materials (Figure 2, e to g) suggests the presence of a laminated surface characteristic of all samples.

\subsection{Computed Tomography $(\mu-C T)$}


244 Extruded materials were scanned using a $\mu$-CT instrument in order to show at a micromolecular level the homogeneity properties and suitability of HME technique to obtain a high mixing degree product. Previous studies to assess drug content uniformity within HME systems incorporated a fluorescent dye (Park et al., 2013) however characterisation of materials internal structure by computed tomography (CT) has gained popularity as a useful tool to examine solid dosage forms such as tablets (Sinka et al., 2004) or granule intermediates (Crean et al., 2010) and more recently co-extruded materials (Vynckier et al., 2015). This technique offers the possibility to analyse the material's internal structure through X-rays scans and visualise density and porosity characteristics. Extruded materials comprising ABZ - PVP K12 at 1/99, $5 / 95$ and 10/90 (\% w/w) were analysed by $\mu$-CT (Fig. 3, a-c) and the cross-section visualised by density characterisation shows an increase in porosity as well as different density levels from low (red) to medium (green) and high (blue) density values that correspond to the densities of air, polymeric material such as PVP K12 and ABZ. The porosity as shown in Figure 3 could be explained by entrapped air or by electrostatic interactions that occurred between ABZ and PVP K12. Moreover, 3D analysis and differences in the morphometric parameters obtained for all extruded materials can be observed in Table 2. It is then evidenced that the degree of porosity is influenced by the drug content within the extruded material and this is the first report of non-homogeneity in extruded materials at a micro-structural level. This is similar to reported micro-structure variations for tablets (Sinka et al., 2004), granules (Crean et al., 2010) and calendered tablets (Vynckier et al., 2015) where it was observed the influence of pores formed during coextrusion into tablet adhesion degree between core and coat. Such studies indicate that despite the known mixing ability of twin-screw processing (Crowley et al., 2007) standard techniques for assessing homogeneity may not be adequate. 
The XRPD patterns of ABZ - PVP K12 extruded formulations, drug-polymer physical mixtures (PM) and pure drug was analysed in order to investigate if any re-crystallisation events registered over time (Figure 4). The XRPD pattern of ABZ shows intensity peaks at $2 \theta$ angles of $6.91,11.32,13.83,17.97,19.51,19.99,20.75,22.19,23.85,24.47,24.72,25.05$, $26.08,26.23,27.21,28.73,29.06,30.00,30.52$ and $31.05^{\circ}$ that correspond to ABZ crystalline form I (Pranzo et al., 2010). However, the intensity of the peak observed at $25^{\circ} 2 \theta$ is lower compared to the one observed by Pranzo et al., (2010). This may be due to specimen preparation errors in the commercial ABZ pattern reported by Pranzo et al., such as crystals non-random preferred orientation (Jenkins and Snyder, 1996).

The XRPD patterns of the physical drug-polymer mixtures (PM) and the extruded materials suggest the absence of a crystalline ordered structure of $\mathrm{ABZ}$ and the formation of an amorphous solid dispersion of the drug within the extruded polymer matrix. It can also be observed that by increasing ABZ content in the physical mixture (PM) samples, the height of the intensity peaks registered also increased (Fig. 4a). In contrast, the extruded materials do not show any intensity peaks relative to crystalline structures but a halo pattern characteristic of amorphous materials. By looking to the XRPD patterns obtained after 6 months storage of the extruded materials containing ABZ - PVP K12 at 10/90 (\% w/w) (Fig. 4b), we can conclude that the materials are stable and there are no re-crystallisation events registered over time. Therefore, these results suggest that stable amorphous solid dispersions of ABZ in PVP K12 for all formulations were achieved.

\subsection{Differential Scanning Calorimetry (DSC)}

DSC analysis of the extruded materials, physical mixtures (PM) and raw materials was carried out to determine the formation of amorphous solid dispersions and also evaluate the presence of glass transition (Tg) events (Fig. 5). Differences between the Tg values of the extruded ABZ formulations and physical mixtures (PM) drug-polymer (differences in scale to 
be considered) indicated that a solid form transformation of the $\mathrm{ABZ}$ crystals occurred during HME and the extruded material thermograms do not show evidence of any endothermic event due to melting of crystalline material. Also, differences regarding Tg appearance is observed and is normally considered a middle value comprised by the Tg values of the raw materials involved (Maru et al., 2011; Baird and Taylor, 2012). Figure 6 shows the DSC thermograms of all extruded materials after 6 months storage. The presence of two Tg events for the 1/99\% (w/w) at $25{ }^{\circ} \mathrm{C}, 5 / 95 \%(\mathrm{w} / \mathrm{w})$ at $25{ }^{\circ} \mathrm{C}, 10 / 90 \%(\mathrm{w} / \mathrm{w})$ at $50{ }^{\circ} \mathrm{C}$ curves suggests that the material could have evolved to a solid glassy suspension. However, there is no evidence of recrystallisation events, conclude that extruded materials are stable over time. Moreover, the $1 / 99 \%(\mathrm{w} / \mathrm{w})$ at $50{ }^{\circ} \mathrm{C}$ and $5 / 95 \%(\mathrm{w} / \mathrm{w})$ at $50{ }^{\circ} \mathrm{C}$ appear to have one $\mathrm{Tg}$ event (solid dispersion), and the $10 / 90 \%(\mathrm{w} / \mathrm{w})$ at $25{ }^{\circ} \mathrm{C}$ shows an amorphous curve without any $\mathrm{Tg}$ events due to the heating rate.

\subsection{Karl-Fischer studies for stability evaluation}

All the raw materials and extruded samples were analysed by Karl-Fischer titration to determine the water content, since the well-known hygroscopicity of some pharmaceutical grade polymers such as polyvinylpyrrolidone (PVP) can be a limitation due to its influence on the stability of amorphous solid dispersions (Bianco et al., 2013). Low water content values of dosage forms containing hygroscopic polymeric materials such as PVP constitute a crucial parameter to be evaluated as there is evidence indicating that intramolecular bonds of polymeric materials and therefore the polymer free volume and other properties like plasticity or elasticity can be affected by increases in water content (Szakonyi and Zelko, 2012). The water content within the samples is a quality attribute to ensure product stability and to preserve the product from degradation phenomena, often known as drug-polymer phase separation events (Rumondor and Taylor, 2009). Table 3 presents the water content (\%) of the raw materials and the ABZ - PVP K12 formulation at 10/90 (\% w/w) observed at zero 
and 6 months after storage. As depicted in Table 3, stored samples did not show water content increase higher than $0.2 \%$ despite the high hygroscopicity properties of PVP. Nonparametric ANOVA (Kruskal-Wallis) test was also performed indicating that temperature changes do not have a significant influence in samples water content $(\mathrm{P}=0.288$ therefore $\mathrm{P}>0.05$ ). Low water content values of $0.2 \%$ are considered optimum for oral dosage forms in order to be stable and preserve their physicochemical properties. Solid dosage forms with water content values below $2 \%$ are considered acceptable for a commercial pharmaceutical product although these values may differ depending on the type of product and specifications required.

\subsection{Dissolution profile studies}

Drug release of the extruded materials was characterised using a Sirius T3 measurement system under non-sink conditions and simulating gastrointestinal (GI) pH conditions. As can be observed in Figure 7, extruded materials (ABZ - PVP K12 ratios of 1/99 and 10/90 (\% w/w)) increased release compared to the pure drug with values of $70 \%$ drug release and

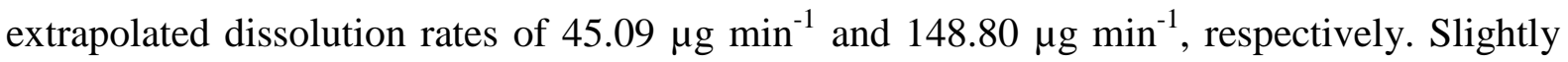
lower values of $50 \%$ drug release and extrapolated dissolution rate value of $171 \mu \mathrm{g} \mathrm{min}{ }^{-1}$ were achieved by the extruded material containing 5/95 (\% w/w). Similar results related to solid dispersions of a BCS Class II drug such as ABZ into a PVP matrix that showed such an increase in drug dissolution rate and a similar dissolution profile were observed by Frizon et al., (2013). Dissolution profiles of the extruded materials of ABZ - PVP K12 at 1/99 and $5 / 95 \%(\mathrm{w} / \mathrm{w}$ ) did not achieve supersaturation (ABZ solubility below $22.8 \mu \mathrm{g} / \mathrm{ml}$ ). However, supersaturation of the system was achieved by ABZ - PVP K12 formulation at 10/90 \% (w/w) with a solubility value of $30.33 \mu \mathrm{g} / \mathrm{ml}$. It is of note in Figures 7 and 8 the increased and fast drug release profile (or also called "spring") of the extruded materials that does not exhibit under the test conditions the characteristic "parachute" effect observed by Brouwers 
et al., (2009). In our studies, an optimum drug release profile close to $100 \%$ was not achieved and possible influence of the polymeric material PVP K12 needs to be further studied. Tablets did completely dissolved in the buffer media which suggests there is an effect of PVP that prevents the complete dissolution of ABZ leading to different proportions (\%) of drug released over time, although this needs to be further studied. Moreover, dissolution studies of the extruded materials stored for 6 months at $25{ }^{\circ} \mathrm{C}$ and $50{ }^{\circ} \mathrm{C}$ revealed that the formulations were stable over time (Fig. 8). Extruded materials comprising 1/99\% (w/w) show a similar dissolution profile after 6 months storage in comparison to 5/95 \% and $10 / 90 \%$ w/w which show variations of approximately $10 \%$ drug release. Similar improvements towards ABZ dissolution rate were achieved by Torrado et al., (1996) that manufactured successful amorphous solid dispersions of ABZ in PVP K12 by the classic solvent evaporation method and also carried out bioavailability studies in animals. We demonstrate the suitability of a lab scale HME process to obtain stable amorphous solid dispersions of $\mathrm{ABZ}$ with enhanced dissolution properties that could lead to novel formulations with enhanced oral bioavailability.

\section{Conclusions}

Amorphous solid dispersions of ABZ, an anthelmintic drug with poor water solubility properties, in PVP K12 matrix were produced by HME method. Evidence of solid form transformation of $\mathrm{ABZ}$ is proved by characterisation of the extruded materials using SEM, XRPD and DSC all of which indicate the formation of an amorphous drug polymer system. We also introduced a novel tool for the characterisation of HME materials, computed tomography $(\mu-\mathrm{CT})$, which provided an insight into internal material properties such as porosity and materials distribution indicating that despite the previous physicochemical results the strands are not homogeneous. The potential impact on pharmaceutical properties will have to be further investigated and maybe mitigated if the strands were pelletised or 
International Journal of Pharmaceutics

369

370

371

372

373

374

375

376

377

378

379

380

381

382

383

384

385

386

387

milled before further processing. Analysis of the samples after 6 months storage did not indicate any drug re-crystallisation events, which suggest that the samples were stable over time. Main factors involved are the use of a polymeric material with high Tg such as PVP $\mathrm{K} 12$ as well as the possibility of a complex formation between the drug and the polymer that will be further studied. High dissolution rate increase of ABZ in gastrointestinal simulated media was achieved with values of $70 \%$ drug release for the extruded materials containing ABZ - PVP K12 at 1/99 and 10/90 (\% w/w). Six months storage under temperature controlled conditions did not affect the dissolution profiles and Karl-Fischer results showed that samples were not affected by water intake. To conclude, HME can be applied as a continuous manufacturing technique of novel oral dosage forms comprising ABZ without the need of further processing techniques in order to improve its dissolution behaviour and possible enhancement of oral bioavailability.

\section{Acknowledgements}

The authors would like to thank EPSRC and the Doctoral Training Centre in Continuous Manufacturing and Crystallisation for funding this work as well as the funding support and collaboration provided by the pharmaceutical companies AstraZeneca (Alderley Park, Cheshire, United Kingdom) and GlaxoSmithKline (Harlow, Essex, United Kingdom). The authors would also like to thank BASF (Cheshire, United Kingdom) for the kind donation of polymeric material. 
International Journal of Pharmaceutics

388

389

390

391

392

393

394

395

396

397

398

399

400

401

402

403

404

405

406

407

408

409

410

\section{References}

Baird, J.A., Taylor, L.S., 2012. Evaluation of amorphous solid dispersion properties using thermal analysis techniques. Advanced drug delivery reviews 64, 396-421.

Bianco, S., Tewes, F., Tajber, L., Caron, V., Corrigan, O.I., Healy, A.M., 2013. Bulk, surface properties and water uptake mechanisms of salt/acid amorphous composite systems. International journal of pharmaceutics 456, 143-152.

Brouwers, J., Brewster, M.E., Augustijns, P., 2009. Supersaturating drug delivery systems: the answer to solubility-limited oral bioavailability?. Journal of pharmaceutical sciences 98 , 2549-2572.

Cheng, H., Friis, A., 2010. Modelling extrudate expansion in a twin-screw food extrusion cooking process through dimensional analysis methodology. Food and Bioproducts Processing 88, 188-194.

Crean, B., Parker, A., Roux, D.L., Perkins, M., Luk, S.Y., Banks, S.R., Melia, C.D., Roberts, C.J., 2010. Elucidation of the internal physical and chemical microstructure of pharmaceutical granules using X-ray micro-computed tomography, Raman microscopy and infrared spectroscopy. European journal of pharmaceutics and biopharmaceutics: official journal of Arbeitsgemeinschaft fur Pharmazeutische Verfahrenstechnik e.V 76, 498-506.

Crowley, M.M., Zhang, F., Repka, M.A., Thumma, S., Upadhye, S.B., Battu, S.K., McGinity, J.W., Martin, C., 2007. Pharmaceutical applications of hot-melt extrusion: part I. Drug development and industrial pharmacy 33, 909-926.

Eitzlmayr, A., Koscher, G., Reynolds, G., Huang, Z., Booth, J., Shering, P., Khinast, J., 2014. Mechanistic modeling of modular co-rotating twin-screw extruders. International journal of pharmaceutics $474,157-176$. 
Forster, A., Hempenstall, J., Tucker, I., Rades, T., 2001. Selection of excipients for melt extrusion with two poorly water-soluble drugs by solubility parameter calculation and thermal analysis. International journal of pharmaceutics 226, 147-161.

414 Frizon, F., Eloy, J.d.O., Donaduzzi, C.M., Mitsui, M.L., Marchetti, J.M., 2013. Dissolution 415 rate enhancement of loratadine in polyvinylpyrrolidone K-30 solid dispersions by solvent methods. Powder Technology 235, 532-539.

417 Gue, E., Willart, J.F., Muschert, S., Danede, F., Delcourt, E., Descamps, M., Siepmann, J., 418 2013. Accelerated ketoprofen release from polymeric matrices: importance of the homogeneity/heterogeneity of excipient distribution. International journal of pharmaceutics 457, 298-307. Jenkins, R., Snyder, R.L., 1996. Introduction to X-ray powder diffractometry. New York 422 Wiley. G.P., 2014. Thermodynamically stable amorphous drug dispersions in amorphous hydrophilic polymers engineered by hot melt extrusion. Chemical Engineering Research and Design 92, 3046-3054.

427 Jung, H., Medina, L., García, L., Fuentes, I., Moreno-Esparza, R., 1998. Biopharmaceutics: absorption studies of albendazole and some physicochemical properties of the drug and its metabolite albendazole sulphoxide. Journal of pharmacy and pharmacology 50, 43-48. poorly water-soluble drugs based on biopharmaceutics classification system: basic approaches and practical applications. International journal of pharmaceutics 420, 1-10. 
International Journal of Pharmaceutics

433 Kawakami, K., 2012. Modification of physicochemical characteristics of active 434 pharmaceutical ingredients and application of supersaturatable dosage forms for improving

435

436

437 bioavailability of poorly absorbed drugs. Advanced drug delivery reviews 64, 480-495.

Kelly, A.L., Halsey, S.A., Bottom, R.A., Korde, S., Gough, T., Paradkar, A., 2015. A novel transflectance near infrared spectroscopy technique for monitoring hot melt extrusion. International journal of pharmaceutics.

Lindenberg, M., Kopp, S., Dressman, J.B., 2004. Classification of orally administered drugs on the World Health Organisation model list of essential medicines according to the Biopharmaceutics Classification System. European journal of pharmaceutics and biopharmaceutics 58, 265-278.

Madan, S., Madan, S., 2012. Hot melt extrusion and its pharmaceutical applications. Asian Journal of Pharmaceutical Sciences 7(2), 123-133.

Maniruzzaman, M., Boateng, J.S., Bonnefille, M., Aranyos, A., Mitchell, J.C., Douroumis, D., 2012. Taste masking of paracetamol by hot-melt extrusion: an in vitro and in vivo evaluation. European journal of pharmaceutics and biopharmaceutics: official journal of Arbeitsgemeinschaft fur Pharmazeutische Verfahrenstechnik e.V 80, 433-442.

Maniruzzaman, M., Morgan, D.J., Mendham, A.P., Pang, J., Snowden, M.J., Douroumis, D., 2013. Drug-polymer intermolecular interactions in hot-melt extruded solid dispersions. International journal of pharmaceutics 443, 199-208.

Marriner, S.E., Morris, D.L., Dickson, B., Bogan, J.A., 1986. Pharmacokinetics of Albendazole in man. European Journal of Clinical Pharmacology 30, 705-708.

Maru, S.M., de Matas, M., Kelly, A., Paradkar, A., 2011. Characterization of thermal and rheological properties of zidovudine, lamivudine and plasticizer blends with ethyl cellulose to assess their suitability for hot melt extrusion. European journal of pharmaceutical sciences: official journal of the European Federation for Pharmaceutical Sciences 44, 471-478. 
Maughan, L., Rhamzan, A., 2012. The evolution of QbD - From inception to maturity in 2012. Reg Rapporteur e.V 9, 9.

Michaeli, W., Frings, W., Höcker, H., Berghaus, U., 1993. Reactive Extrusion of Styrene Polymers. International Polymer Processing 8, 308-318.

Moyano, J.R., Liró, J., Pérez, J.I., Arias, M.J., Sánchez-Soto, P.J., 2014. Thermal analysis of Albendazole investigated by HSM, DSC and FTIR. Microscopy: advances in scientific research and education (A. Méndez-Vilas, Ed.), 1043-1050.

Munos, B., 2009. Lessons from 60 years of pharmaceutical innovation. Nature reviews. Drug discovery 8, 959-968.

Newman, A., Knipp, G., Zografi, G., 2012. Assessing the performance of amorphous solid dispersions. Journal of pharmaceutical sciences 101, 1355-1377.

Park, J.B., Kang, C.Y., Kang, W.S., Choi, H.G., Han, H.K., Lee, B.J., 2013. New investigation of distribution imaging and content uniformity of very low dose drugs using hot-melt extrusion method. International journal of pharmaceutics 458, 245-253.

Pranzo, M.B., Cruickshank, D., Coruzzi, M., Caira, M.R., Bettini, R., 2010. Enantiotropically related albendazole polymorphs. Journal of pharmaceutical sciences 99, 3731-3742.

Reintjes, T., 2011. Solubility enhancement with BASF pharma polymers. Solubilizer Compendium.

Repka, M.A., Battu, S.K., Upadhye, S.B., Thumma, S., Crowley, M.M., Zhang, F., Martin, C., McGinity, J.W., 2007. Pharmaceutical applications of hot-melt extrusion: Part II. Drug development and industrial pharmacy 33, 1043-1057.

Rumondor, A.C.F., Taylor, L.S., 2009. Effect of Polymer Hygroscopicity on the Phase Behavior of Amorphous Solid Dispersions in the Presence of Moisture. Molecular Pharmaceutics 7, 477-490. 
International Journal of Pharmaceutics

482

483

484

485

486

487

488

489

490

491

492

493

494

495

496

497

498

499

500

501

502

503

504

Sarode, A.V., Kumbharkhane, A.C., 2012. Dielectric relaxation and thermodynamic properties of polyvinylpyrrolidone using time domain reflectometry. Polymer International 61, 609-615.

Schilling, S.U., McGinity, J.W., 2010. Novel application of hot-melt extrusion for the preparation of monolithic matrices containing enteric-coated particles. International journal of pharmaceutics 400, 24-31.

Sinka, I.C., Burch, S.F., Tweed, J.H., Cunningham, J.C., 2004. Measurement of density variations in tablets using X-ray computed tomography. International journal of pharmaceutics 271, 215-224.

Stegemann, S., Leveiller, F., Franchi, D., De Jong, H., Lindén, H., 2007. When poor solubility becomes an issue: From early stage to proof of concept. European journal of pharmaceutical sciences 31, 249-261.

Szakonyi, G., Zelko, R., 2012. The effect of water on the solid state characteristics of pharmaceutical excipients: Molecular mechanisms, measurement techniques, and quality aspects of final dosage form. International journal of pharmaceutical investigation 2, 18-25.

Thiry, J., Krier, F., Evrard, B., 2015. A review of pharmaceutical extrusion: Critical process parameters and scaling-up. International journal of pharmaceutics 479, 227-240.

Torrado, S., Torrado S., Torrado, J.J., Cadórniga, R., 1996. Preparation, dissolution and characterization of albendazole solid dispersions. International journal of pharmaceutics 140, $247-250$

Van Zuilichem, D.J., Kuiper, E., Stolp, W., Jager, T., 1999. Mixing effects of constituting elements of mixing screws in single and twin screw extruders. Powder Technology 106, 147159. 
505 Verhoeven, E., Siepmann, F., De Beer, T.R., Van Loo, D., Van den Mooter, G., Remon, J.P., 506 Siepmann, J., Vervaet, C., 2009b. Modeling drug release from hot-melt extruded mini507 matrices with constant and non-constant diffusivities. European journal of pharmaceutics and 508 biopharmaceutics: official journal of Arbeitsgemeinschaft fur Pharmazeutische 509 Verfahrenstechnik e.V 73, 292-301.

510 Vynckier, A.K., Lin, H., Zeitler, J.A., Willart, J.F., Bongaers, E., Voorspoels, J., Remon, J.P., 511 Vervaet, C., 2015. Calendering as a direct shaping tool for the continuous production of 512 fixed-dose combination products via co-extrusion. European Journal of Pharmaceutics and 513 Biopharmaceutics.

514 Zhang, G.G., Law, D., Schmitt, E.A., Qiu, Y., 2004. Phase transformation considerations 515 during process development and manufacture of solid oral dosage forms. Advanced drug 516 delivery reviews 56, 371-390. 
International Journal of Pharmaceutics

519

520

521

522

523

524

525

526

527

528

529

530

531

532

533

534

535

536

537

538

539

540

\section{Figure captions}

Figure 1: Hot-stage microscopy (HSM, 10x magnification) images a to d: pure $\mathrm{ABZ}$ at $80{ }^{\circ} \mathrm{C}$, $145^{\circ} \mathrm{C}, 180{ }^{\circ} \mathrm{C}$ and $210{ }^{\circ} \mathrm{C}$, images e to g: physical mixture (PM) ABZ - PVP K12 at 10/90 (\% w/w) at $80{ }^{\circ} \mathrm{C}, 145^{\circ} \mathrm{C}$ and $180{ }^{\circ} \mathrm{C}$.

Figure 2: SEM images of pure drug (a), physical mixtures ABZ - PVP K12 at 1/99, 5/95 and $10 / 90(\% \mathrm{w} / \mathrm{w})(\mathrm{b}$ to d) and extruded materials of ABZ - PVP K12 formulation at 1/99, 5/95 and $10 / 90(\% \mathrm{w} / \mathrm{w})$ (e to g).

Figure 3: Micro-CT single scanned images of extruded materials of ABZ - PVP K12 at 1/99, $5 / 95$ and $10 / 90 \%(w / w)(a, b$ and $c)$.

Figure 4: Diffractograms of (a) ABZ - PVP K12 formulations at time zero and (b) ABZ PVP K12 at a 10/90 (\% w/w) ratio after 6 months storage.

Figure 5: DSC thermograms of a: pure ABZ, b to d: physical mixtures (PM) of ABZ - PVP $\mathrm{K} 12$ at 1/99 (\% w/w), 5/95 (\% w/w) and 10/90 (\% w/w) and e to g: extruded materials of ABZ - PVP K12 at 1/99 (\% w/w), 5/95 (\% w/w) and 10/90 (\% w/w).

Figure 6: DSC thermograms after 6 months storage where a: extruded material of ABZ PVP K12 at $1 / 99 \%(\mathrm{w} / \mathrm{w})$ at $25^{\circ} \mathrm{C}$, b: extruded material of ABZ - PVP K12 at 1/99 \% (w/w) at $50{ }^{\circ} \mathrm{C}$, c: extruded material of $\mathrm{ABZ}-\mathrm{PVP} \mathrm{K} 12$ at $5 / 95 \%(\mathrm{w} / \mathrm{w})$ at $25{ }^{\circ} \mathrm{C}$, d: extruded material of $\mathrm{ABZ}-\mathrm{PVP} \mathrm{K} 12$ at $5 / 95 \%(w / w)$ at $50{ }^{\circ} \mathrm{C}$, e: extruded material of $\mathrm{ABZ}-\mathrm{PVP}$ $\mathrm{K} 12$ at $10 / 90 \%(\mathrm{w} / \mathrm{w})$ at $25{ }^{\circ} \mathrm{C}$ and f: extruded material of $\mathrm{ABZ}-\mathrm{PVP} \mathrm{K} 12$ at $10 / 90 \%$ (w/w) at $50^{\circ} \mathrm{C}$.

Figure 7: Dissolution profiles simulating gastrointestinal conditions of a: pure ABZ, b to d: physical mixtures (PM) of ABZ - PVP K12 at 10/90 (\% w/w), 5/95 (\% w/w) and 1/99 (\% 
International Journal of Pharmaceutics

$541 \mathrm{w} / \mathrm{w})$ and e to g: extruded materials of ABZ - PVP K12 at 5/95 (\% w/w), 1/99 (\% w/w) and $54210 / 90(\% \mathrm{w} / \mathrm{w})$. Standard error bars are based on 2 tests per sample.

543 Figure 8: Dissolution profiles simulating gastrointestinal conditions, upper left image 544 (extruded material of ABZ - PVP K12 at 1/99\% (w/w)): a: pure ABZ, b: extrudate at time 545 zero, c: extrudate after 6 months storage at $50{ }^{\circ} \mathrm{C}$, d: extrudate after 6 months storage at 25 $546{ }^{\circ} \mathrm{C}$; Upper right image (extruded material of ABZ - PVP K12 at 5/95\% (w/w)): a: pure ABZ, 547 b: extrudate after 6 months storage at $25^{\circ} \mathrm{C}$, c: extrudate after 6 months storage at $50{ }^{\circ} \mathrm{C}$, d: 548 extrudate at time zero; Lower image (extruded material of ABZ - PVP K12 at 10/90\% 549 (w/w)): a: pure ABZ, b: extrudate after 6 months storage at $25^{\circ} \mathrm{C}$, c: extrudate at time zero, 550 d: extrudate after 6 months storage at $50{ }^{\circ} \mathrm{C}$. 
International Journal of Pharmaceutics

Table 1. HME processing parameters of ABZ - PVP K12 formulations

\begin{tabular}{|c|c|c|c|c|c|}
\hline $\begin{array}{c}\text { HME } \\
\text { formulation }\end{array}$ & $\begin{array}{c}\text { Barrel } \\
\text { Zones }\end{array}$ & $\begin{array}{c}\text { Barrel temperatures } \\
\left({ }^{\circ} \mathbf{C}, \text { zones 1, 2, 3 and 4-8) }\right.\end{array}$ & $\begin{array}{c}\text { Screw } \\
\text { speed } \\
(\mathbf{r p m})\end{array}$ & $\begin{array}{c}\text { Torque } \\
(\mathbf{N m})\end{array}$ & $\begin{array}{c}\text { Throughput } \\
(\mathbf{K g} / \mathbf{h})\end{array}$ \\
\hline $\mathrm{F} 1$ & $1-8$ & $70,120,140,145$ & 100 & $1.2-3$ & $0.1-0.15$ \\
\hline F2 & $1-8$ & $70,120,140,145$ & 100 & $1.2-3$ & 0.15 \\
\hline F3 & $1-8$ & $70,120,140,145$ & 100 & $1.2-2.7$ & $0.1-0.15$ \\
\hline
\end{tabular}

\section{Description:}

Table 1 shows the HME processing parameters applied for the development of three formulations comprising Albendazole (ABZ) and PVP K12 such as barrel temperatures and screw speed. Further information such as the torque values registered and the total throughput are also given. 
International Journal of Pharmaceutics

553 Table 2. Morphometric parameters of extruded materials obtained by $\mu$-CT 3D analysis

\begin{tabular}{|c|c|c|c|}
\hline $\begin{array}{c}\text { HME } \\
\text { formulation }\end{array}$ & $\begin{array}{c}\text { Object volume } \\
\left(\mathbf{m m}^{\mathbf{3}}\right)\end{array}$ & $\begin{array}{c}\text { Volume closed } \\
\text { pores }\left(\mathbf{m m}^{\mathbf{3}}\right)\end{array}$ & Closed porosity (\%) \\
\hline $\mathrm{F} 1$ & 25.17 & 0.01 & 0.04 \\
\hline $\mathrm{F} 2$ & 26.17 & 0.65 & 2.43 \\
\hline $\mathrm{F} 3$ & 12.70 & 0.20 & 1.57 \\
\hline
\end{tabular}

554

\section{Description:}

555 Table 2 above shows the $\mu$-CT 3D analysis of the extruded materials such as the object

556 volume, defined as the total volume analysed based on the external dimensions of the strand

557 (diameter approximately $2.0 \mathrm{~mm}$ ) and the closed pores, defined as the space within the object

558 volume, which is completely surrounded by solid material. 
International Journal of Pharmaceutics

Table 3. Karl-Fischer results after storage

\begin{tabular}{|c|c|c|}
\hline Materials & Storage conditions & Average water content $(\%$ w/w $)$ \\
\hline \multirow{2}{*}{$\begin{array}{c}\text { Extruded material } \\
\mathrm{ABZ}-\mathrm{PVP} \mathrm{K} 1210 / 90 \\
(\% \text { w/w }) \text { ratio }\end{array}$} & Time zero, room temperature & $0.1591 \pm 0.0084$ \\
\cline { 2 - 3 } & 6 months at $25^{\circ} \mathrm{C}, 20 \% \mathrm{RH}$ & $0.1445 \pm 0.0387$ \\
\cline { 2 - 3 } & 6 months at $50^{\circ} \mathrm{C}, 3 \% \mathrm{RH}$ & $0.1796 \pm 0.0037$ \\
\hline
\end{tabular}

\section{Description:}

Table 3 above shows the average water content values $(\% \mathrm{w} / \mathrm{w})$ obtained by Karl-Fischer coulometric titration using methanol as dissolution media. Mean standard deviation (SD) values of 3 replicates calculated for each sample are depicted using \pm symbol (Kruskal-Wallis test, $\mathrm{P}=0.288$ therefore $\mathrm{P}>0.05)$. 